\title{
Bis(aryl) Tetrasulfides as Cathode Materials for Rechargeable Lithium Batteries
}

\author{
Wei Guo, ${ }^{[a][e]}$ Zachary D. Wawrzyniakowski, ${ }^{[b]}$ Matthew M. Cerda, ${ }^{[d]}$ Amruth \\ Bhargav, ${ }^{[\mathrm{a}]}$ Michael D. Pluth,*[d] Ying Ma, ${ }^{*[c]}$ and Yongzhu Fu*[a]
}

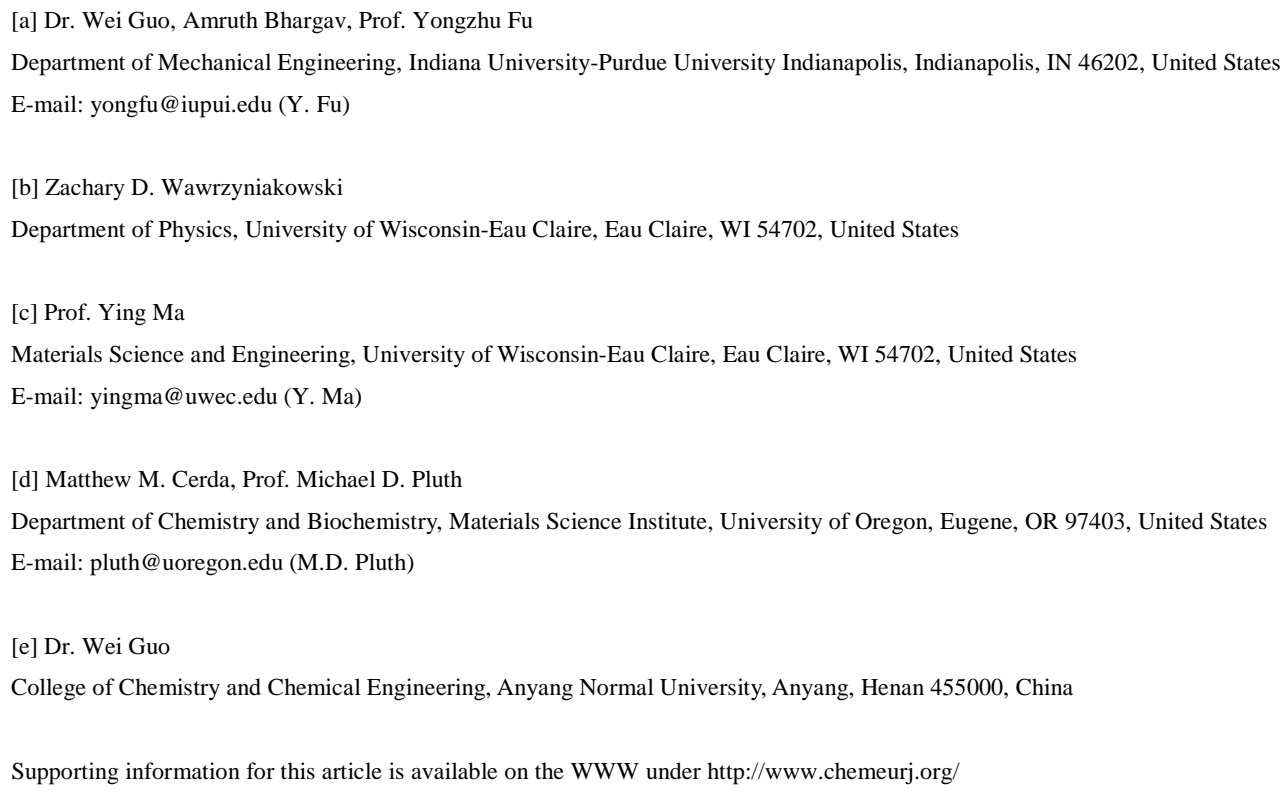

Keywords: rechargeable lithium battery $\bullet$ organopolysulfide $\bullet$ bis(aryl) tetrasulfide $\bullet$ catholyte $\bullet$ theoretical calculation

Abstract: An organotetrasulfide consists of a linear chain of four sulfur atoms that could accept up to $6 \mathrm{e}^{-}$in reduction reactions, thus providing a promising high-capacity electrode material. Herein, we study three bis(aryl) tetrasulfides as cathode materials in lithium batteries. Each tetrasulfide exhibits two major voltage regions in the discharge. The high voltage slope region is governed by the formation of persulfides and thiolates, and the low voltage plateau region is due to the formation of $\mathrm{Li}_{2} \mathrm{~S}_{2} / \mathrm{Li}_{2} \mathrm{~S}$. Based on theoretical calculations and spectroscopic analysis, three reduction reaction processes are revealed, and the discharge products are identified. Lithium half cells with tetrasulfide catholytes deliver high specific capacities over 200 cycles. The effects of the functional groups on the electrochemical characteristics of tetrasulfides are

This is the author's manuscript of the article published in final edited form as: 
investigated, which provides guidance for developing optimum aryl polysulfides as cathode materials for high energy lithium batteries.

Energy storage is rising to an unprecedented level of importance in the utilization of intermittent renewable energies, such as solar and wind. ${ }^{[1]}$ Energy storage technologies that can enable advanced portable devices and electric vehicles are also critical. Rechargeable batteries are one of the most promising and practical choices for these applications due to the low-cost, high reliability, and long cycle life. ${ }^{[2]}$ Li-ion batteries have the highest energy density compared to other aqueous electrolyte-based counterparts, (e.g., lead-acid and nickel-metal hydride batteries) and are not only widely used in portable electronics but also hold promise for electric vehicles and grid energy storage. ${ }^{[3]}$ The lithium storage capacity $\left(<250 \mathrm{mAh} \mathrm{g}^{-1}\right)$ in Li-ion batteries is limited, however, by the transition metal oxide cathode materials. To further increase the energy density of rechargeable lithium batteries, alternative electrode materials with higher specific capacities are highly needed. ${ }^{[4]}$

Sulfur-based cathodes have shown promising properties and performance, such as abundance and high specific capacities (1,675 mAh $\left.\mathrm{g}^{-1}\right)$, which could enable high energy density lithium batteries,. ${ }^{[5]}$ A remaining challenge, however, is that elemental sulfur is prone to form lithium polysulfides (i.e., $\mathrm{Li}_{2} \mathrm{~S}_{\mathrm{x}}, 4 \leq \mathrm{x} \leq 8$ ) during discharge and charge 
cycling, which results in the shuttle effect and short cycle life. Some approaches have been developed to overcome these issues, ${ }^{[6]}$ such as using nano carbon hosts, ${ }^{[7]}$ applying polysulfide absorbers, ${ }^{[8]}$ and developing novel cell configurations. ${ }^{[9]}$ Organopolysulfides, as a form of sulfur compounds, possess unique properties that could overcome some issues associated with lithium polysulfides. Recently, organotrisulfides such as methyl trisulfide $\left(\mathrm{CH}_{3} \mathrm{~S}_{3} \mathrm{CH}_{3}\right)$ and phenyl trisulfide $\left(\mathrm{C}_{6} \mathrm{H}_{5} \mathrm{~S}_{3} \mathrm{C}_{6} \mathrm{H}_{5}\right)$ that can accept up to $4 \mathrm{e}^{-}$per molecule have shown promising electrochemical performance. ${ }^{[10]}$ To further increase specific capacities, high order organopolysulfides are needed.

Motivated by this unmet need, we report here the use of phenyl tetrasulfide (PTS, $\mathrm{C}_{6} \mathrm{H}_{5} \mathrm{~S}_{4} \mathrm{C}_{6} \mathrm{H}_{5}$ ) and related derivatives as cathode materials for rechargeable lithium batteries for the first time. The tetrasulfides were synthesized by the treatment of parent thiols with $\mathrm{S}_{2} \mathrm{Cl}_{2}$ and pyridine, as recently reported to access analytically-pure tetrasulfides. ${ }^{[11]}$ The phenyl rings not only improve cycling stability, ${ }^{[10 b]}$ but also provide sites for attaching functional groups that can be used to tune the electronic and physical properties of each tetrasulfide. The functional group can be $\mathrm{OCH}_{3}, \mathrm{CH}_{3}, \mathrm{~F}, \mathrm{CF}_{3}$, and $\mathrm{N}\left(\mathrm{CH}_{3}\right)_{2}$ etc. In this study, we selected two derivatives for comparison, including p-methoxyphenyl tetrasulfide ( $\mathrm{CH}_{3} \mathrm{OPTS}$ ), which contains an electron-donating $\mathrm{OCH}_{3}$ group, and p-trifluoromethylphenyl tetrasulfide ( $\left.\mathrm{CF}_{3} \mathrm{PTS}\right)$, which contains an 
electron-withdrawing $\mathrm{CF}_{3}$ group. The tetrasulfide moiety in these molecules can be reduced by taking up to $6 \mathrm{e}^{-}$and $6 \mathrm{Li}^{+}$, affording them with theoretical specific capacities of $569.3 \mathrm{mAh} \mathrm{g}^{-1}, 469.5 \mathrm{mAh} \mathrm{g}^{-1}$, and $384.3 \mathrm{mAh} \mathrm{g}^{-1}$ for PTS, $\mathrm{CH}_{3} \mathrm{OPTS}$, and $\mathrm{CF}_{3} \mathrm{PTS}$, respectively, as shown in Scheme 1. We use electrochemical techniques, first-principle density functional theory (DFT) calculations, and spectroscopic analysis to investigate the electrochemical characteristics of these compounds in rechargeable lithium batteries. This study intends to explore the new class, high-capacity tetrasulfides with particular structures and correlate their structure-property-performance relationship, which will help design higher order organopolysulfides such as pentasulfides and hexasulfides.

The tetrasulfides are either yellow solids ( $\mathrm{CH}_{3} \mathrm{OPTS}$ ) or viscous yellow liquids (PTS and $\mathrm{CF}_{3} \mathrm{PTS}$ ) at room temperature and are all instantly miscible with the ether-based liquid electrolyte that is widely used in Li-S battery studies, rendering $0.5 \mathrm{M}$ or $0.2 \mathrm{M}$ catholytes that can be evaluated in lithium half cells directly. The low catholyte concentrations and high electrolyte/active material ratios used in this study are needed to maintain a relatively stable lithium metal anode which consumes blank electrolyte upon cycling, so that we can evaluate the true electrochemical behavior of the cathode materials. Carbon nanotube (CNT) paper was used as the current collector on the cathode which also serves as an effective reservoir for holding discharged and charged products 
upon cycling. This cell configuration has been successfully used in previous studies with polysulfide and organotrisulfide catholytes. ${ }^{[10,12]}$

Cyclic voltammograms (CV) and the voltage profiles of the three tetrasulfides are shown in Figures 1a-c, which reveal their redox characteristics. During the initial cathodic scan from open circuit voltage to $1.8 \mathrm{~V}$, all samples show three cathodic peaks. Peak currents in peaks III are all shown at $2.0 \mathrm{~V}$, whereas peaks I and II show up at different higher potentials. The discharge voltage profiles can be separated into two regions: high voltage slope region $(>2.1 \mathrm{~V})$ and low voltage plateau region $(\sim 2.1 \mathrm{~V})$. The middle voltages in the high voltage regions are in the order of $\mathrm{CH}_{3} \mathrm{OPTS}(2.18 \mathrm{~V})<\mathrm{PTS}$ $(2.22 \mathrm{~V})<\mathrm{CF}_{3} \mathrm{PTS}(2.30 \mathrm{~V})$, which agrees with the electron accepting ability of $\mathrm{OCH}_{3}, \mathrm{H}$, and $\mathrm{CF}_{3}$ groups. During the following anodic scan from $1.8 \mathrm{~V}$ to $3.0 \mathrm{~V}$ in the $\mathrm{CV}$, overlapping anodic peaks are observed. The charge voltage profiles also exhibit two regions. The cells with PTS and $\mathrm{CH}_{3} \mathrm{OPTS}$ show long voltage plateaus followed by short voltage slopes at the end of charge. However, the cell with $\mathrm{CF}_{3} \mathrm{PTS}$ shows two almost equivalent voltage plateaus. The voltage hysteresis between charge and discharge are also in the order of $\mathrm{CH}_{3} \mathrm{OPTS}<\mathrm{PTS}<\mathrm{CF}_{3} \mathrm{PTS}$, indicating the cell with $\mathrm{CH}_{3} \mathrm{OPTS}$ has the lowest overpotential.

To further investigate the discharge processes, first-principles DFT calculations 
were performed. The equilibrium geometries and electrostatic potentials, which are the interaction energies of the molecules with a positive ion, are shown in Figure 1d. As expected, the sulfur atoms in the chain are the lithiation sites on these molecules. To further understand where the reduction reactions start, the S-S bond energies were calculated and are summarized in Figure 1e. The $\alpha$-sulfur is the one bonded to the phenyl ring and the $\beta$-sulfur is the one next to the $\alpha$-sulfur. The $\beta$-sulfur bond $\left(\mathrm{S}_{\beta}-\mathrm{S}_{\beta}\right)$ energies (1.43-1.45 eV) are much lower than the $\alpha$-sulfur and $\beta$-sulfur bond $\left(\mathrm{S}_{\alpha}-\mathrm{S}_{\beta}\right)$ energies (1.68-1.87 eV), indicating the $\mathrm{S}_{\beta}-\mathrm{S}_{\beta}$ bonds break when the reduction reactions start. Therefore, the first reduction reaction in the discharge is: R-S-S-S-S-R $+2 \mathrm{Li} \rightarrow$ 2R-S-S-Li (reaction 1), which forms two aryl persulfides. Figure 1f shows the lowest unoccupied molecular orbital (LUMO) configurations of the three tetrasulfides and their LUMO and highest occupied molecular orbital (HOMO) energies. The LUMO energy falls in the order of $\mathrm{CF}_{3} \mathrm{PTS}<\mathrm{PTS}<\mathrm{CH}_{3} \mathrm{OPTS}$, indicating the reduction potentials in the reaction 1 are in the order of $\mathrm{CH}_{3} \mathrm{OPTS}<\mathrm{PTS}<\mathrm{CF}_{3} \mathrm{PTS}$. The two R-S-S-Li molecules formed in the first step will subsequently react through: 2R-S-S-Li $+2 \mathrm{Li} \rightarrow 2 \mathrm{R}-\mathrm{S}-\mathrm{Li}+$ $\mathrm{Li}_{2} \mathrm{~S}_{2}$ (reaction 2). Reactions 1 and 2 could take place simultaneously at different molecular sites leading to overlapped slopes in the high voltage regions in all three molecules. The LUMO and HOMO energies of the aryl persulfides (Figure S1 in 
Supporting Information) demonstrate that the energy difference $(0.65 \mathrm{eV})$ between the LUMO energy level of $\mathrm{CF}_{3}$ PTS $(-1.21 \mathrm{eV})$ and the corresponding aryl persulfide, i.e., $\mathrm{CF}_{3} \mathrm{C}_{6} \mathrm{H}_{4} \mathrm{SSLi}(-0.56 \mathrm{eV})$, is much larger than those in PTS $(0.42 \mathrm{eV})$ and $\mathrm{CH}_{3} \mathrm{OPTS}$ (0.28 eV), indicating that the first reduction (reaction 1) of $\mathrm{CF}_{3} \mathrm{PTS}$ is more favorable, and thus provides a more stable plateau region. When $\mathrm{Li}_{2} \mathrm{~S}_{2}$ is formed in reaction 2 , the voltage drops to about $2.1 \mathrm{~V}$. The low voltage plateau is indicative of the conversion reaction: $\mathrm{Li}_{2} \mathrm{~S}_{2}+2 \mathrm{Li} \rightarrow 2 \mathrm{Li}_{2} \mathrm{~S}$ (reaction 3) which is similar to that in Li-S battery chemistry. ${ }^{[13]}$

To identify the discharge products of these tetrasulfides, X-ray photoelectron spectroscopy (XPS) was performed, and the sulfur spectra are shown in Figure 2a. All three samples show two pairs of doublet peaks. The pairs of doublet peaks with the S 2p $3 / 2$ peaks centered at $160.2 \mathrm{eV}$ are assigned to the sulfur in $\mathrm{Li}_{2} \mathrm{~S}^{[14]}$ which is the $\beta$-sulfur in tetrasulfides, indicating $\mathrm{Li}_{2} \mathrm{~S}$ is one of the discharged products. The other pairs of doublet peaks in these samples are assigned to the sulfur in aryl thiolates (i.e., $\mathrm{C}_{6} \mathrm{H}_{5} \mathrm{SLi}$, $\mathrm{CH}_{3} \mathrm{OC}_{6} \mathrm{H}_{4} \mathrm{SLi}$, and $\mathrm{CF}_{3} \mathrm{C}_{6} \mathrm{H}_{4} \mathrm{SLi}$ ), which is the $\alpha$-sulfur in tetrasulfides. The three $\mathrm{S} 2 \mathrm{p}_{3 / 2}$ peaks have small binding energy differences, which are in the order of $\mathrm{CH}_{3} \mathrm{OC}_{6} \mathrm{H}_{4} \mathrm{SLi}<$ $\mathrm{C}_{6} \mathrm{H}_{5} \mathrm{SLi}<\mathrm{CF}_{3} \mathrm{C}_{6} \mathrm{H}_{4} \mathrm{SLi}$ as expected from their electron-donating or electron withdrawing behavior. The $\alpha$-sulfur peak intensities are much lower than those of the $\beta$-sulfur, which is 
due to the washing process causing most aryl thiolates to be washed away.

To further understand the discharges of these compounds, we turned to X-ray diffraction (XRD) and scanning electron microscopy (SEM)/energy-dispersive X-ray spectroscopy (EDS). The XRD results in Figure S2 show that the three discharged electrodes are almost amorphous. The main crystalline peaks at $2 \theta=26^{\circ}$ are known as the (002) crystal planes of CNTs. ${ }^{[15]}$ The SEM and EDS images of the washed, discharged electrodes are shown in Figure 2b-d. The PTS electrode shows a porous morphology indicating most soluble species (e.g., LiTFSI and $\mathrm{C}_{6} \mathrm{H}_{5} \mathrm{SLi}$ ) were removed during the washing process. The CNTs are coated with insoluble sulfur species, which are believed to be amorphous $\mathrm{Li}_{2} \mathrm{~S}$ and some residual $\mathrm{C}_{6} \mathrm{H}_{5} \mathrm{SLi}$. The elemental mappings of carbon and sulfur evidently validate that the discharged products are homogeneously distributed in the discharged electrode. The CNTs maintain a self-weaving network in the discharged electrode forming continuous electron conducting pathways. In contrast, the $\mathrm{CH}_{3} \mathrm{OPTS}$ and $\mathrm{CF}_{3} \mathrm{PTS}$ electrodes are much less porous. The $\mathrm{CH}_{3} \mathrm{OPTS}$ electrode is uniformly filled and covered with sulfur species having some nano fringes facilitating ion and charge transport, whereas the $\mathrm{CF}_{3} \mathrm{PTS}$ electrode shows large and isolated particles which can result in high overpotential. This observation is believed to be related to the electrolyte compatibility of tetrasulfides, with the addition of the $-\mathrm{OCH}_{3}$ group enhancing and the 
$-\mathrm{CF}_{3}$ group decreasing the compatibility with the ether electrolyte, respectively.

After investigating the chemical transformations of these tetrasulfides, we further explore their electrochemical performance in lithium half cells. Figure 3a presents the cycling performance of cells with $0.5 \mathrm{M}$ catholytes at C/10. The mass loadings are $2.8 \mathrm{mg}$ $\mathrm{cm}^{-2}$ (PTS), $3.4 \mathrm{mg} \mathrm{cm}^{-2}$ ( $\mathrm{CH}_{3} \mathrm{OPTS}$ ), and $4.2 \mathrm{mg} \mathrm{cm}^{-2}$ ( $\mathrm{CF}_{3} \mathrm{PTS}$ ). The lithium half cells deliver initial discharge specific capacities of $486 \mathrm{mAh} \mathrm{g}^{-1}$ PTs, $324 \mathrm{mAh} \mathrm{g}^{-1}$ CHзOPTs, and $272 \mathrm{mAh} \mathrm{g}^{-1}$ CF3PTs and retain 74\%, 81\%, and 43\% of the initial capacities over 100 cycles, respectively. The cycling stability is in the order of $\mathrm{CF}_{3} \mathrm{PTS}<\mathrm{PTS}<\mathrm{CH}_{3} \mathrm{OPTS}$. The electrochemical performance of PTS is comparable to that of phenyl trisulfide, ${ }^{[10 \mathrm{~b}]}$ but with much higher specific capacities. All cells show a stable Coulombic efficiency of above $97.5 \%$ after the first cycles. The discharge specific capacities obtained are lower than the theoretical capacities of these tetrasulfides, which is due to the relatively high active material mass loadings. When the catholyte concentration was reduced to $0.2 \mathrm{M}$, much higher initial discharge capacities were obtained as shown in Figure $3 \mathbf{b}$. The capacity retention is about $60 \%$ over 200 cycles. Clearly, PTS shows the highest discharge capacities due to its lowest molecular weight, the $\mathrm{CH}_{3} \mathrm{OPTS}$ electrode shows the lowest overpotential and highest cycling stability because of the electrolyte-compatible $\mathrm{OCH}_{3}$ group. The $\mathrm{CF}_{3} \mathrm{PTS}$ electrode shows the lowest discharge 
capacities due to its highest molecular weight and poorest cycling performance. The voltage profiles in different cycles are shown in Figure S3. The major capacity loss of the $\mathrm{CF}_{3} \mathrm{PTS}$ electrode is shown in the low voltage plateau, which is reduced more than $80 \%$ after 100 cycles. The inhomogeneity of the discharged electrode shown in the SEM image results in poor reversibility of the $\beta$-sulfur back to the oxidation reaction shown in Scheme 1 after $\mathrm{Li}_{2} \mathrm{~S}$ is formed. The effects of the functional group $\mathrm{X}$ on the properties and electrochemical characteristics of aryl tetrasulfides are summarized in Figure 3c.

In summary, we have demonstrated the fidelity of three bis(aryl) tetrasulfides as potential high-capacity cathode materials for rechargeable lithium batteries. Our studies reveal the discharge processes and electrochemical characteristics of these tetrasulfides, and the observed high specific capacities are appealing for battery application. Importantly, the ease of structural modification of the tetrasulfides provides the opportunity to specifically tune electronic properties, and therefore the resulting electrochemical behavior in tetrasulfide-based lithium batteries. Moreover, the findings in this work provide new insights and guidance for developing optimum organopolysulfides as cathode materials for high energy rechargeable lithium batteries. 


\section{Experimental Section}

Materials: Thiophenol was purchased from Alfa Aesar. Sulfur monochloride and 4-methoxythiophenol was purchased from Sigma-Aldrich. 4-(Trifluoromethyl)benzene thiol was purchased from Toyko Chemical Industry (TCI). Lithium bis(trifluoromethanesulfonimide) (LiTFSI, $\mathrm{LiN}\left(\mathrm{CF}_{3} \mathrm{SO}_{2}\right)_{2}, 99 \%$, Acros Organics), lithium nitrate $\left(\mathrm{LiNO}_{3}, 99.999 \%\right.$, Acros Organics), 1,2-dimethoxyethane (DME, 99.5\%, Sigma Aldrich), and 1,3-dioxolane (DOL, 99.8\%, Sigma Aldrich) were purchased. All reagents were used as received.

Preparation of bis(aryl) tetrasulfides: Details about the synthesis and characterization of bis(aryl) tetrasulfides are described in the previous report. ${ }^{[11]}$

Electrolyte and catholyte preparation: The ether electrolyte is composed of $1.0 \mathrm{M}$ LiTFSI and 0.2 $\mathrm{M} \mathrm{LiNO}_{3}$ in mixture solvent of DME and DOL (1:1 v/v). To prepare catholytes, tetrasulfides were dissolved in the electrolyte to render $0.5 \mathrm{M}$ or $0.2 \mathrm{M}$ solutions.

Li/catholyte cell fabrication and electrochemical evaluation: Commercial binder-free carbon nanotube paper called buckypaper (NanoTechLabs, Inc) was used as the current collector in this study. The carbon paper was cut into $\sim 0.97 \mathrm{~cm}^{2}$ discs $(\mathrm{D}=11 \mathrm{~mm}$, about $2 \mathrm{mg}$ each) and dried at $100{ }^{\circ} \mathrm{C}$ for $24 \mathrm{~h}$ in a vacuum oven before use. CR2032 coin cells 
were used and the cells were made in an Ar-filled glove box. First, $20 \mu \mathrm{L} 0.5 \mathrm{M}$ or $0.2 \mathrm{M}$ catholyte was added into the current collector. The tetrasulfide loadings are $2.8 \mathrm{mg}$ (PTS), $3.4 \mathrm{mg}\left(\mathrm{CH}_{3} \mathrm{OPTS}\right)$, and $4.2 \mathrm{mg}\left(\mathrm{CF}_{3} \mathrm{PTS}\right)$ and the active material mass/carbon ratios in the electrodes are 1.4, 1.7, and 2.1, respectively, when $0.5 \mathrm{M}$ catholytes were used. Then, a Celgard 2400 separator was placed on the top of the electrode followed by adding 20 $\mu \mathrm{L}$ blank electrolyte on the separator. Finally, a piece of lithium foil and nickel foam as a spacer was placed on the separator. The cell was crimped and taken out of the glove box for the electrochemical evaluation.

Cyclic voltammetry (CV) was performed on a BioLogic VSP potentiostat. The potential was swept from open circuit voltage to $1.8 \mathrm{~V}$ and then cycled between 1.8 and $3.0 \mathrm{~V}$ at a scanning rate of $0.05 \mathrm{mV} \mathrm{s}^{-1}$. Cells were galvanostatically cycled on an Arbin BT2000 battery cycler at $\mathrm{C} / 10$ rates. $1 \mathrm{C}=569 \mathrm{~mA} \mathrm{~g}^{-1}$ for PTS, $1 \mathrm{C}=470 \mathrm{~mA} \mathrm{~g}^{-1}$ for $\mathrm{CH}_{3} \mathrm{OPTS}$, and $1 \mathrm{C}=384 \mathrm{~mA} \mathrm{~g}^{-1}$ for $\mathrm{CF}_{3} \mathrm{PTS}$.

\section{Characterizations:}

The X-ray diffraction (XRD) data of the discharged electrodes were collected on a Bruker D8 Discover XRD Instrument equipped with $\mathrm{Cu} \mathrm{K} \alpha$ radiation. The scanning rate was $2^{\circ}$ $\min ^{-1}$, and $2 \theta$ was set between $20^{\circ}$ and $60^{\circ}$. The discharged electrodes of tetrasulfides were protected by a Kapton tape and characterized with the same procedure. The 
morphological characterization of the cycled electrodes was conducted with a JEOL JSM-7800F field emission scanning electron microscopy (SEM). The elemental mapping was performed with energy-dispersive X-ray spectroscopy (EDS) attached to the SEM. X-ray photoelectron spectroscopy (XPS) experiments were performed using PHI Versa Probe II instrument equipped with focused monochromatic Al $\mathrm{K} \alpha$ source. The X-ray power of $50 \mathrm{~W}$ at $15 \mathrm{kV}$ was used for $200 \mu \mathrm{m}$ beam size. The PHI dual charge compensation system was used on all samples. XPS spectra with the energy step of $0.1 \mathrm{eV}$ were recorded using software SmartSoft-XPS v2.0 and processed using Casa 2.317 software. The spectrum was calibrated using HOPG strips attached alongside the samples as standard and setting its $\mathrm{C}$ 1s binding energy (BE) to $284.4 \mathrm{eV}$ and verified using adventitious (aliphatic) carbon BE. The XPS spectra were fitted using a combination of Gaussians and Lorentzians with 0-50\% of Lorentzian contents. Shirley background was used for curve-fitting. The $\mathrm{S} 2 \mathrm{p}_{3 / 2}$ and $\mathrm{S} 2 \mathrm{p}_{1 / 2}$ doublets were constrained using peak areas of 2:1 with a splitting of $1.18 \mathrm{eV}$. Cells for the XPS analysis were cycled using $20 \mu \mathrm{L} 0.2 \mathrm{M}$ catholytes at C/10 till the cut-off voltage at $1.8 \mathrm{~V}$. The cells were then opened, the cathode was extracted, washed using DME and dried in glovebox atmosphere before mounting on instrument sample holders. The samples were transferred to the instrument in an argon-filled airtight container. 


\section{Computational Section:}

First principles calculations based on the density functional theory (DFT) were performed using SPARTAN software package (Wave function, Irvine, CA), and the M06-2X exchange-correlation functional ${ }^{[16]}$ and the $6-31 G^{*}$ basis set were used. The equilibrium structures of different molecules were determined through geometry optimization, and then total energy calculations were performed to obtain the bond energies and LUMO/HOMO levels. The effects of solvent were simulated using a polarizable continuum model (PCM), and the dielectric constant was set to that of DME that was used as electrolyte in this study (the dielectric constant of DOL is similar to that of DME).

\section{Acknowledgements}

YF acknowledges the Release Time for Research grant from Office of the Vice Chancellor for Research, the Integrated Nanosystems Development Institute for use of JEOL7800F Field Emission SEM (NSF MRI-1229514) and Bruker D8 Discover XRD (NSF MRI-1429241) at Indiana University-Purdue University Indianapolis. YF also thanks the Nanoscale Characterization Facility at Indiana University for the XPS measurements. ZW and YM would like to thank the Materials Science and Engineering Center at the University of Wisconsin-Eau Claire for financial support. MDP acknowledges support from the NSF (CHE-1454747) for polysulfide synthesis and applications.

Received: ((will be filled in by the editorial staff))

Revised: ((will be filled in by the editorial staff)) Published online: ((will be filled in by the editorial staff)) 
[1] a) B. Dunn, H. Kamath, J.-M. Tarascon, Science 2011, 334, 928-935; b) Z. Yang, J. Zhang, M. C. W. Kintner-Meyer, X. Lu, D. Choi, J. P. Lemmon, J. Liu, Chem. Rev. 2011, 111, 3577-3613.

[2] M. Winter, R. J. Brodd, Chem. Rev. 2004, 104, 4245-4270.

[3] J. B. Goodenough, Y. Kim, Chem. Mater. 2010, 22, 587-603.

[4] P. G. Bruce, S. A. Freunberger, L. J. Hardwick, J.-M. Tarascon, Nat. Mater. 2012, $11,19-29$.

[5] a) A. Manthiram, Y.-Z. Fu, S.-H. Chung, C.-X. Zu, Y.-S. Su, Chem. Rev. 2014, 114, 11751-11787; b) Y.-X. Yin, S. Xin, Y.-G. Guo, L.-J. Wan, Angew. Chem. Int. Ed. 2013, 52, 13186-13200.

[6] Q. Pang, X. Liang, C. Y. Kwok, L. F. Nazar, Nat. Energy 2016, 1, 16132.

[7] a) X. Ji, K. T. Lee, L. F. Nazar, Nat. Mater. 2009, 8, 500-506; b) N. Jayaprakash, J. Shen, S. S. Moganty, A. Corona, L. A. Archer, Angew. Chem. Int. Ed. 2011, 50, 5904-5908; c) J. Guo, Y. Xu, C. Wang, Nano Lett. 2011, 11, 4288-4294; d) S. Xin, L. Gu, N.-H. Zhao, Y.-X. Yin, L.-J. Zhou, Y.-G. Guo, L.-J. Wan, J. Am. Chem. Soc. 2012, 134, 18510-18513; e) J. Zhang, C.-P. Yang, Y.-X. Yin, L.-J. Wan, Y.-G. Guo, Adv. Mater. 2016, 28, 9539-9544.

[8] a) X. Ji, S. Evers, R. Black, L. F. Nazar, Nat. Commun. 2011, 2, 325; b) X. Tao, J. Wang, C. Liu, H. Wang, H. Yao, G. Zheng, Z. W. Seh, Q. Cai, W. Li, G. Zhou, C. Zu, Y. Cui, Nat. Commun. 2016, 7, 11203; c) Z. Yuan, H.-J. Peng, T.-Z. Hou, J.-Q. Huang, C.-M. Chen, D.-W. Wang, X.-B. Cheng, F. Wei, Q. Zhang, Nano Lett. 2016, 16, 519-527; d) X. Liu, J.-Q. Huang, Q. Zhang, L. Mai, Adv. Mater. 2017, 29, 1601759.

[9] a) Y.-S. Su, A. Manthiram, Nat. Commun. 2012, 3, 1166; b) C. Huang, J. Xiao, Y. Shao, J. Zheng, W. D. Bennett, D. Lu, L. V. Saraf, M. H. Engelhard, L. Ji, J. Zhang, X. Li, G. L. Graff, J. Liu, Nat. Commun. 2014, 5, 3015; c) M. Liu, X. Qin, Y.-B. He, B. Li, F. Kang, J. Mater. Chem. A 2017, 5, 5222-5234.

[10] a) M. Wu, Y. Cui, A. Bhargav, Y. Losovyj, A. Siegel, M. Agarwal, Y. Ma, Y.-Z. Fu, Angew. Chem. Int. Ed. 2016, 55, 10027-10031; b) M. Wu, A. Bhargav, Y. Cui, A. Siegel, M. Agarwal, Y. Ma, Y.-Z. Fu, ACS Energy Lett. 2016, 1, 1221-1226.

[11] M. M. Cerda, M. D. Hammers, M. S. Earp, L. N. Zakharov, M. D. Pluth, Org. Lett. 2017, 19, 2314-2317.

[12] Y.-Z. Fu, Y.-S. Su, A. Manthiram, Angew. Chem. Int. Ed. 2013, 52, 6930-6935.

[13] a) C. Barchasz, F. Molton, C. Duboc, J.-C. Lepretre, S. Patoux, F. Alloin, Anal. Chem. 2012, 84, 3973-3980; b) R. Xu, J. Lu, K. Amine, Adv. Energy Mater. 2015, 5, 1500408. 
[14] X. Liang, C. Hart, Q. Pang, A. Garsuch, T. Weiss, L. F. Nazar, Nat. Commun. 2015, 6, 5682.

[15] M. Wu, J. Wang, Z. Wu, H. Xin, D. Wang, J. Mater. Chem. A 2015, 3, 7727-7731.

[16] Y. Zhao, D. G. Truhlar, Theor. Chem. Acc. 2006, 120, 215-241. 


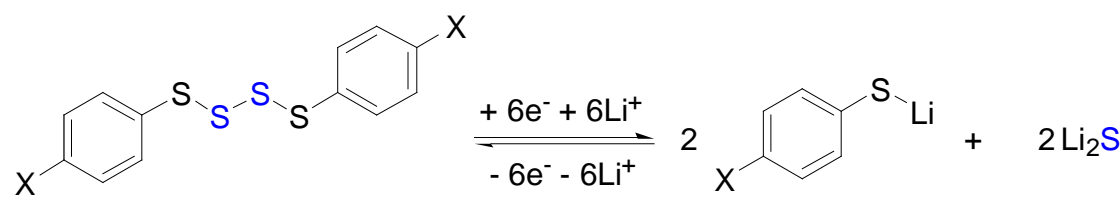

\begin{tabular}{l|ll}
$\mathrm{X}$ & M.W. $\left(\mathrm{g} \mathrm{mol}^{-1}\right)$ & S.C. $\left(\mathrm{mAh} \mathrm{g}^{-1}\right)$ \\
\hline $\mathrm{H}$ & 282.5 & 569.3 \\
$\mathrm{OCH}_{3}$ & 342.5 & 469.5 \\
$\mathrm{CF}_{3}$ & 418.5 & 384.3
\end{tabular}

Scheme 1. Potential chemical transformations of three representative bis(aryl) tetrasulfides in rechargeable lithium batteries, and molecular weights (M.W.) and theoretical specific capacities (S.C.) of these molecules. 
a)

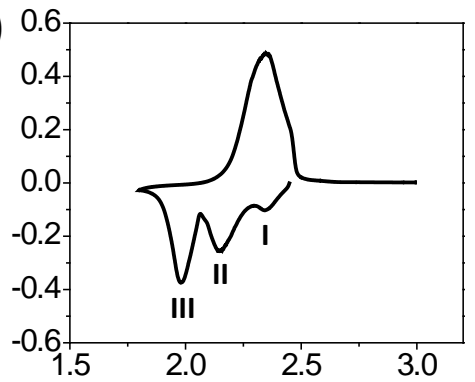

b)

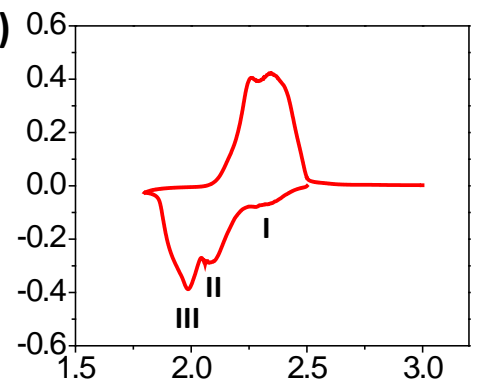

c)

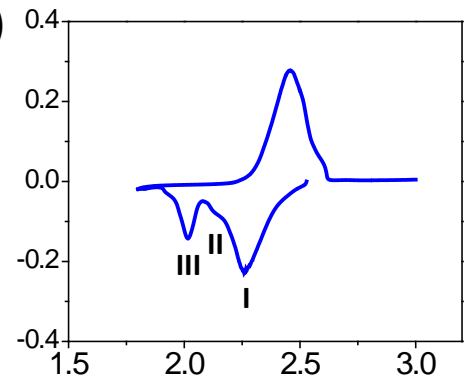

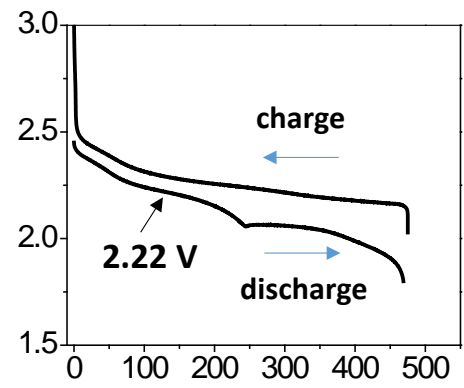

d)
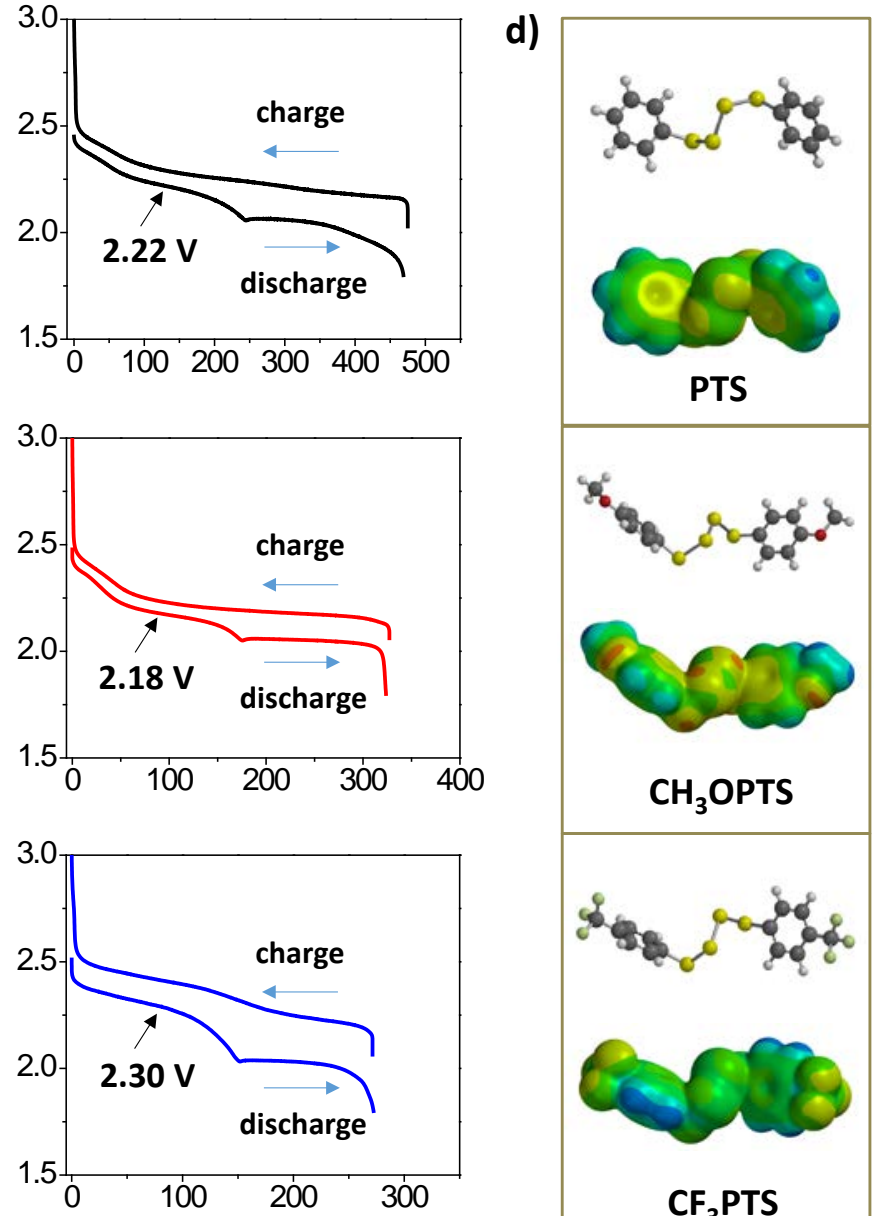

PTS

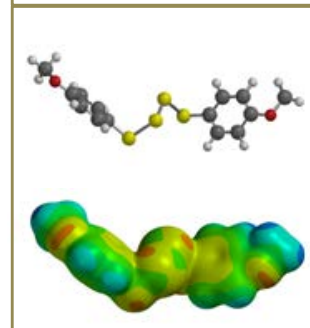

$\mathrm{CH}_{3} \mathrm{OPTS}$

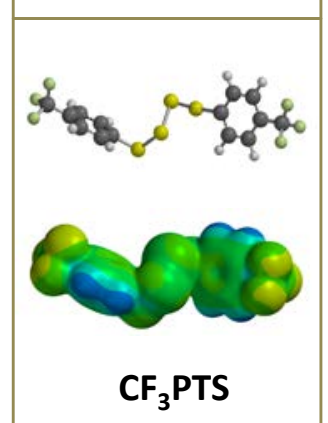

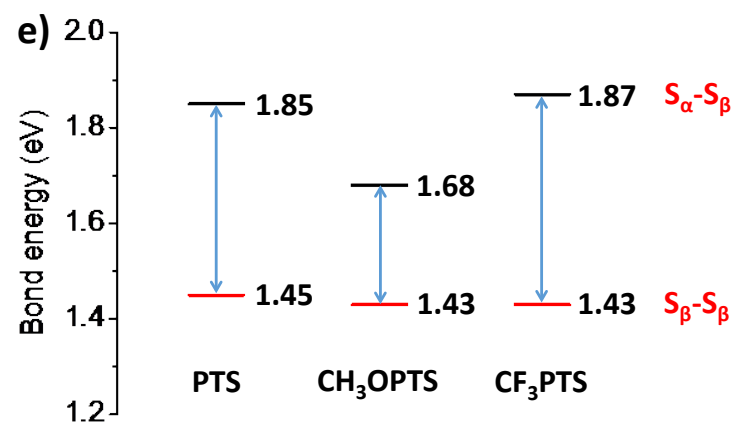

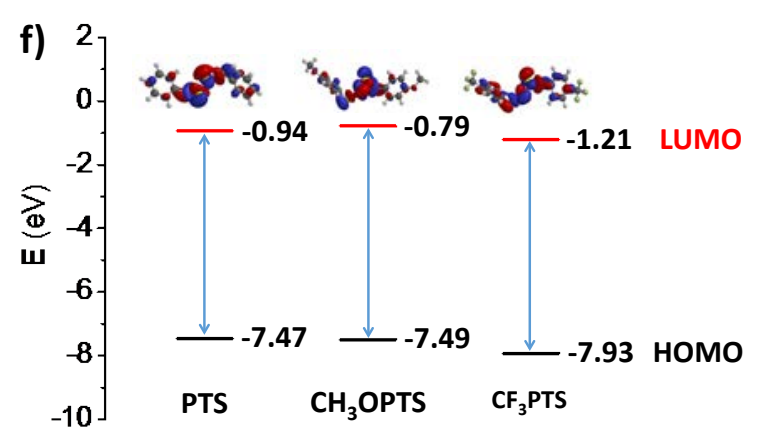

Figure 1. Cyclic voltammetry (CV) and voltage profile of lithium half cells with a) PTS, b) $\mathrm{CH}_{3} \mathrm{OPTS}$, and c) $\mathrm{CF}_{3} \mathrm{PTS}$ electrodes. d) Equilibrium structures and electrostatic potentials of tetrasulfides. Note that colors toward red correspond to a negative potential, while colors toward blue correspond to a positive potential. e) Sulfur-sulfur bond energies in tetrasulfides. The $\alpha$-sulfur is the one bonded to the phenyl ring and the $\beta$-sulfur is the one next to the $\alpha$-sulfur. f) LUMO configurations, where the blue color indicates a positive phase whereas the red color refers to a negative phase, and LUMO/HOMO energy levels of tetrasulfides. 

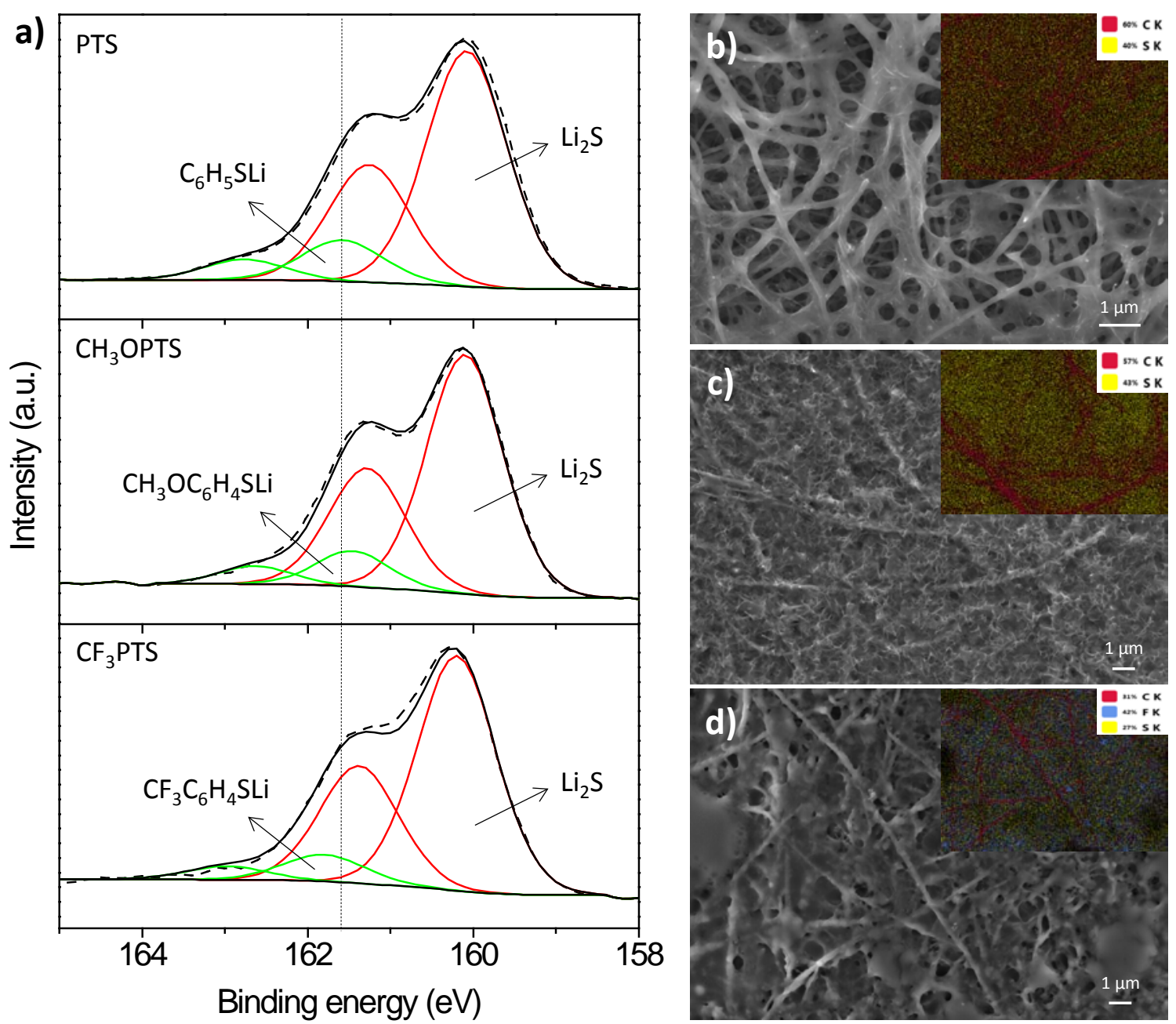

Figure 2. a) Sulfur 2p XPS spectra of the fully discharged electrodes of tetrasulfides. SEM images of b) PTS, c) $\mathrm{CH}_{3} \mathrm{OPTS}$, and d) $\mathrm{CF}_{3}$ PTS discharged electrodes. The insets are EDS images with carbon (red) and sulfur (yellow). 
a)

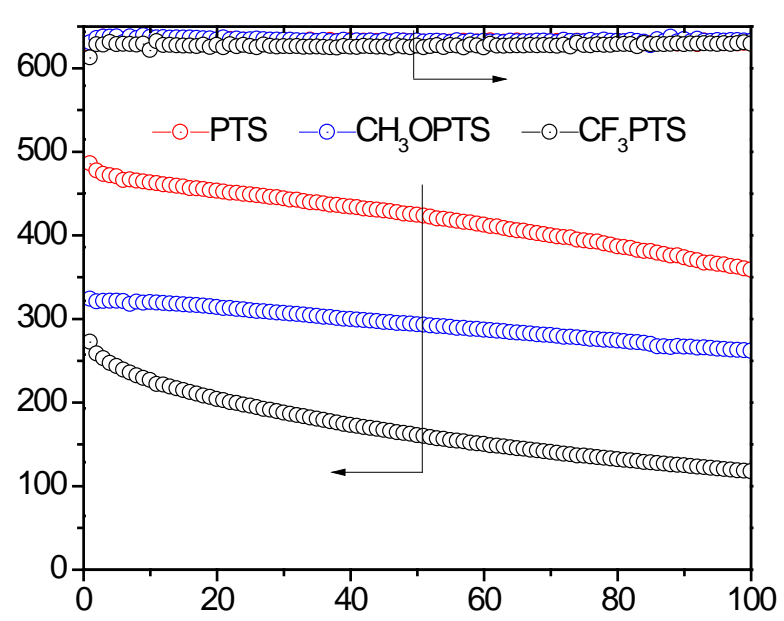

b)

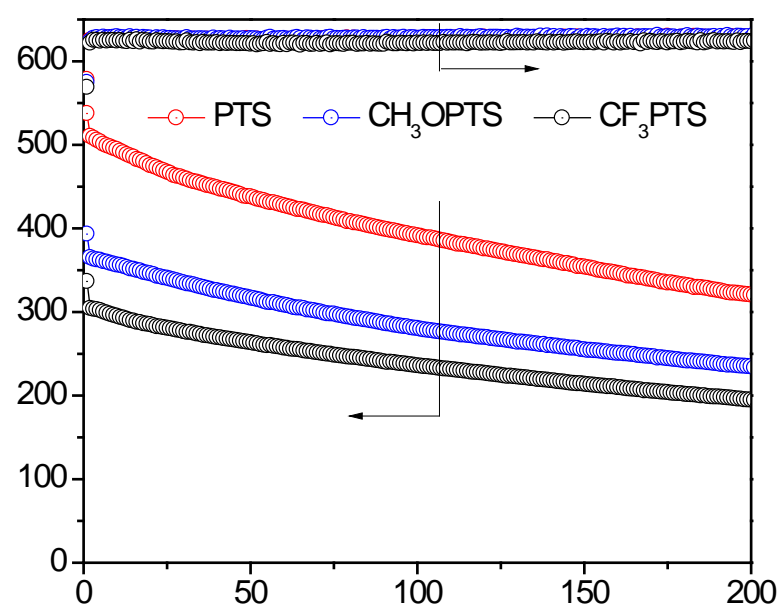

c)

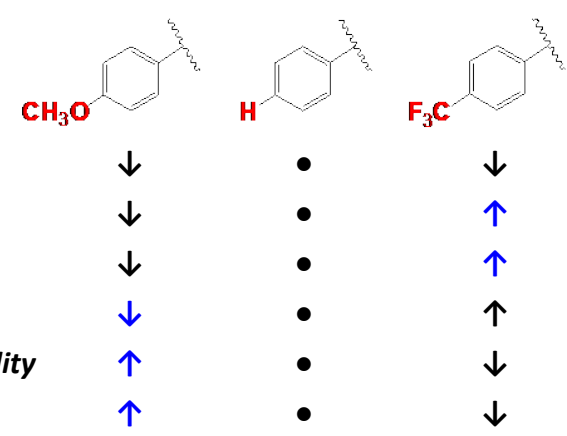

Figure 3. a) Cycling performance of tetrasulfide catholytes $(0.5 \mathrm{M})$ at $\mathrm{C} / 10$ rate. b) Cycling performance of tetrasulfide catholytes $(0.2 \mathrm{M})$ at $\mathrm{C} / 2$ rate. c) Effects of functional groups on phenyl rings on the properties and electrochemical characteristics of bis(aryl) tetrasulfides, positive effects are highlighted in blue. 


\section{Entry for the Table of Contents}

Wei Guo, Zachary D. Wawrzyniakowski, Matthew M. Cerda, Amruth Bhargav, Michael D. Pluth, * Ying Ma, * and Yongzhu Fu*

\section{Bis(aryl) Tetrasulfides as Cathode Materials for Rechargeable Lithium Batteries}

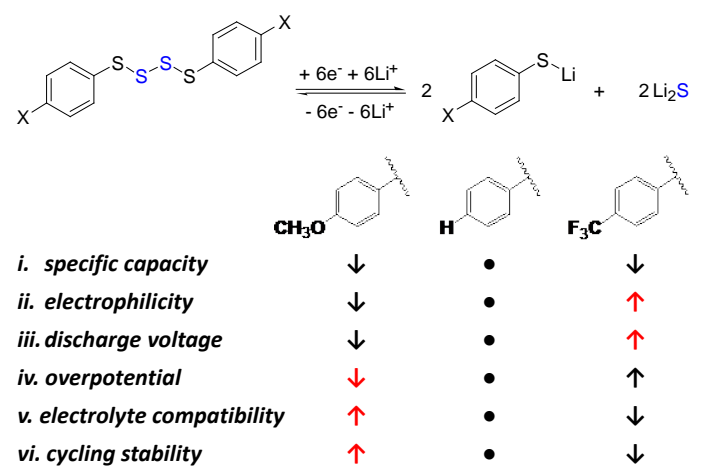

In this report, three bis(aryl) tetrasulfides were studied as cathode materials in

rechargeable lithium batteries. Based on theoretical calculations and spectroscopic

analysis, three reduction reaction processes are revealed, and the discharge products are

identified. Lithium half cells with tetrasulfide catholytes deliver high specific capacities

over 200 cycles. The effects of the functional groups on the electrochemical

characteristics of tetrasulfides are investigated. 